\title{
The Market Hydrocarbons in Commercial Contracts
}

\author{
Mcs. Vladimir Mici \\ Lecturer Mediterranean University of Albania
}

\section{Doi:10.5901/mjss.2014.v5n16p166}

\begin{abstract}
This article aims through an economic model to explain its impact on prices of contracts Albanian market. Even the Albanian market today in the field of fuel appear structured and rules that are reflected in regular contracts between producers and merchants and dealers and consumers. These contracts are extended for periods of more 1,3,6,12 and thereby create a market for the purchase and sale of such contracts and sub contracts under the counter under a market. Through an economic model, we aim to give the effect and role in the award of contracts and the amount that they cover. This is an evaluation model that can be extended to its market hidrokarbureve.Konkluzionet are real, as is proved that the Albanian market monopoly and oligopolistic behavior reflects market prices and growing trend in prices
\end{abstract}

Keywords: Contrate, Fuel, Model; Price; forward, market. Albania

\section{Preface}

Albania is an active market in the area of hydrocarbons. This, as a result of the fact that Albania has become an export country of raw petroleum, but at the same time is a big consumer of fuel itself. There are more than 30 trade companies that furnish fuel in large quantities, but that do also function in the trade distribution of small quantities too. On the other hand, the small distribution stations that are not generally white points provide their furnishing from these traders. As such, the situation becomes problematic as far as Albanian economy is concerned as well as the impact that these prices mean for our economy.

This has caused the creation of rather those casual rapports, the institutionalization of the actions between producing and furnishing subjects on one part and the consummator subjects on the other hand, in the form of monthly, three monthly annual and several years' contracts up to five years contracts. The contract market has become necessary even from the quality viewpoint as these prices or quantities depend on the game that produces and consumers of raw petrol are playing today in the world. Raw petrol determines the fuel prices, as this is an excellent case of illustrating the effect of the impact of prices of commodities.

The practice of these last years shows a high instability, that makes the sector of raw petrol the main market of future contrate and the contracts of the future, anywhere in the world. The index of price raise in commodities has brought the chain reaction in a market that tries to get fixed by different countries governments and policies. This is how from time to time there are price explosions whose effect is more powerfully felt in total consumption.

Of course, the object of all this is to understand, how contracts can impact the spot prices. The Albanian case is not identical, but observing that the production of petrol sub products, mainly gasoil and gasoline which are imported products in almost above $95 \%$ of the quantity, which makes the market research transfer in bringing raw petrol prices outside the country.

As a result, contract trade has developed even from our firms, especially those in the area of fuel, which invest in contract binding for gasoil and gasoline. Even though there does not exist such a clear price market, this does not hinder neither petrol stations, not large petrol companies cooperate or exchange contracts demonstrating the most elementary form of a forward trade. Thus, this is a market, where contracts are bought and sold.

So, on one hand we have a contract market that demonstrates the requirements of companies for stabilized fuel and with prices prior set in the signed contracts and on the other hand contracts that traders (either high or small quantity traders) have signed with their clients.

And also there are traders that purchase or sell without a contract signed making use of the price of the moment or the spot price. Here there are in the case of purely commercial exchanges, but we counter market under contracts

This article investigates the cooperation between the spot and forward market within a model based on the economics analysis. This model aims at bringing new elements of the analysis of contract market especially and role of 
traders.

The model aims at clearing some aspects of the fuel market, keeping open a contract market, where consumers and producers might trade fuel in the future. This is opening the door to traders, whose agents buy fuel and resell it or decide on the deals between buyers and sellers for the whole market. These traders might either be independent or as part of branches of fuel producers or deliverers.

In this model we foresee some limitations:

1. It does not allow for suppliers to decide upon quantities or sign the schedule of a spot market. So, they do not have any control over spot prices.

2. Both suppliers and consumers behave competively in the contract market.

The theories of models in this direction have not been missing around the interaction between spot prices and contract prices. Their main model is a two period game model (duopol), where producers firstly purchase or sell forward contracts (either supplied or obvious) and then, during the second period it plays a cournot game in the quantities of a spot market. They represent first of all the producers that have got a high incentive on selling their part of forwrd production, but when it hapens that one of them is the only forward trader, he makes a big profit out of operating in such a way. Trading in forward markets is a prisoning dilemma for producers, in case when they end up worse than when they traded for spot markets. Also, these models demonstrate the fact that cournot spot market and forward market are efficient within limits, when the number of selling periods goes to infinite.

\section{Fuel Market}

The model of fuel market consists of two fuel trade categories.

The first category includes those that sell fuel in big quantites, fuel producers as well as fuel traders who are also producers.

The second category includes the petrol stations that have to require all of their requested foreseen quantity upon a contract.

Contracts have been created based on an inner auction of each company, within their time limit functionality that is for one, three or five years after the auction date and divided per auction for an adding quantity of fuel or the existing quantity. Contracts for fuel are usually for longer than one year.

The secondary trade environment is called the environment of free contracting and brings together traders, independent fuel producers, importers, exporters and free consumers (the ones that need not purchase fuel from the big companies in Albania e.g. Kurum, Bankers etc.) Purchasers and sellers are free to enter bilateral contracts and negotiate prices, quantities and time limits along with conditions. Traders might be either independent or branches of the producers or delivery companies. They might purchase, repurchase, sell or resell fuel or just finish deals between sellers and purchasers.

The difference between contracted fuel and fuel that has effectively been produced or consummed from market agents that have been liquidated through spot market are called te liquidation of prices of difference. It is simply a mecanism of many scales cleaning of over suppliance or lack of fuel.

The requirement is to find a model that optimizes costs versus prices.

\section{Model and Findings}

We are interested on the impact of fuel traders in the fuel market. In order to achieve this we need to model two separated markets which are interconnected : the contract market and the spot market. Apart from this we need to take into consideration the fact that contract market is divided into two sub markets: the fixed market and the free market.

\subsection{Contract Market}

Free consumers do not purchase in the fixed market (the contract market), so we do not need to model a connection between this and the free market for as far as the demand is determined. As about the offer we make the supposition that producers sell in both markets, first in the fixed market and then in the free one. When the decision about how much they need to sell is taken, then they are able to commit in the fixed market according to the reached agreement. This supposition makes sense, if we take into account the fact that producers present their offers in the auction within fixed market and enter long term contracts with delivery companies, in case their offers are successful. We aim at creating the possible opportunities for valuable strategic behaviour for offerers as a result of their presence in both markets in future 
business.

The spot market is modelled as a mecanism producing a casual spot price. This price is in return dependent upon the request for fuel predicted by the store and treatment capacity of the system.

\subsection{Contract market with one trader (producer)}

There are two modeling periods. During the zero period a forward contract market with $\mathrm{n}$ bidding suppliers (with the $\mathrm{k}$ index), $\mathrm{m}$ consumers (with the i index) and an open trader. Society publicly advertizes the predicted request to be used in calculating the spot price for period 1 and the traders purchases forward contracts by the bidding supplier and sells them to the consumer with a premium. The spot market opens in period 1, when there are differences between the contracted amount and the requested amount, represented in the spot price. Forward contracts have been set in period 1. As we mentioned previously, the spot market is a casual mechanism that produces a spot price $p$. We model the spot price as a casual variable

\section{$\mathrm{P}=\mathrm{a}-\mathrm{bQ} \mathrm{Q}^{\mathrm{e}}+\mathrm{W}$}

(equation 1)

Where $\mathrm{Q}^{\mathrm{e}}$ is the predicted request and $\mathrm{w}$ is the casual variable with normal average delivery $\mathrm{m}$ and variance $\mathrm{v}^{2}$. Both suppliers and consumers have a refusal to risk and a negative exponent usefulness function, which is given by $u(p)$ $=-e^{-a p}$ where $p$ is the gain.

The function of consumers gain is:

$\Pi_{i}{ }^{c}=r_{i} f_{i}\left(R_{i}\right)-p\left(R_{i}-y_{i}{ }^{c}\right)-q^{c} y_{i}{ }^{c}-c_{i j} f_{i}\left(R_{i}\right)$

where $q^{c}$ is the price of a contracted litra qouted by the trader for the consumer $r_{i}$ is the price for small amounts given to his product and $R_{i}$ is the actual fuel amount used by the consumer to produce $f_{i}\left(R_{i}\right)$ units of his product, $f_{i}$ is the function of his production, $\mathrm{c}_{\mathrm{i}}$ is the constant marginal cost (and average) and $\mathrm{yi}^{\mathrm{c}}$ is the amount purchased through forward contracts.

Revenues in equation 2 are equal to revenues that the consumer produces with volume $R_{i}$ of fuel (we call it a free consumer in a forward market that is a producer in a market of his own products) multiplied by the small amounts prices of his product.

We equal the cost of marginal product with zero, so that part of the gain cost of the i consumer includes only the cost of purchasing fuel in the spot market and the cost of fuel purchase in the contract market. It is observed that the quantity that it purchases in the spot market is the difference between the purchased quantity and that purchased in the contract market.

As the function of consumer utility has got a negative exponential form, the problem of gain maximisation might be expressed in terms of safely equivalent measurement:

$\operatorname{MaxE}\left(\Pi_{i} \mathrm{c}\right)-\mathrm{a}_{\mathrm{i}}^{\mathrm{c}} /\left[2 \operatorname{Var}\left(\Pi_{i} \mathrm{c}\right)\right]$ where $\mathrm{a}_{\mathrm{i}}^{\mathrm{c}}$ is the coefficient of risk refusal.

Before being able to calculate the expected value and the gain variance of the i consumer, we need to understand how it forms its expectation around sales in the product market. It would not be practical to model the market product of each consumer, so we suppose that it might be perfectly predicted based on how many products might be produced and sold during period 1.

When $R_{i}$ is given and

$E\left(\Pi_{i} \mathrm{c}\right)=r_{i} f_{i}\left(R_{i}\right)-p-\left(R_{i}-y_{i}{ }^{c}\right)-q^{c} y_{i}{ }^{c}-c_{i j}\left(R_{i}\right)$ then $\operatorname{Var}$ is

$\left.\operatorname{Var}\left(\Pi_{i} \mathrm{c}\right)\right]=\operatorname{Var}\left(\mathrm{rif}_{\mathrm{i}}\left(\mathrm{R}_{\mathrm{i}}\right)-\mathrm{p}\left(\mathrm{R}_{\mathrm{i}}-\mathrm{y}_{\mathrm{i}}^{\mathrm{c}}\right)-\mathrm{q}^{\mathrm{c}} \mathrm{y}_{\mathrm{i}}^{\mathrm{c}}-\mathrm{c}_{\mathrm{i}} \mathrm{f}_{\mathrm{i}}\left(\mathrm{R}_{\mathrm{i}}\right)=\left(\mathrm{R}_{\mathrm{i}} \mathrm{y}_{\mathrm{i}}^{\mathrm{c}}\right) \mathrm{s}^{2}\right.$

Where $p=a-b Q^{e}+m$ is the predicted value of the spot price

The solution to the problem is :

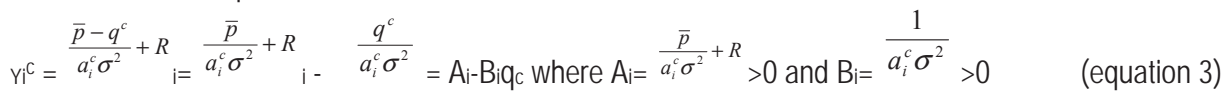

The offer is a price taking method in both markets: contract and spot markets. So, the gain function would be given by the formulae:

$$
\begin{aligned}
& \stackrel{g}{\Pi^{k}}=\stackrel{g}{g}\left(\mathrm{~F}_{\mathrm{k}}-\mathrm{y}^{k}\right)+\mathrm{q}^{\mathrm{g}} \mathrm{y}^{k}-\mathrm{V}_{\mathrm{k}} \mathrm{F}_{\mathrm{k}} \\
& \text { (equation 4) }
\end{aligned}
$$

Where $\mathrm{y}^{k}$ is the product amount to be sold forward, $\mathrm{q}^{g}$ is the price for fuel unit offered from the trader to the supplier, $F_{k}$ is the actual fuel production from net suppliers in sales in a fixed market (through contracts) and $v_{k}$ is its marginal constant cost (and average).

In the above formulation the offer supplier must know the amount that he will be asked to produce, in period 1, so 
that he will know the amount of fuel that he has to sell through the contract. We make a simple supposition, that the offer suppliers are symmetrical and each of them would want to produce the quantity of fuel that satisfies all the required quantity predicted by the request makers.

So, $F_{k}=\left(Q^{e} / n\right)-F^{k}$ for all $k$ where $F^{k}$, is the amount of fuel sold through contract services. What is more, we might make marginal costs zero, without general loss. We observe then, according to the given definition we have:

$$
\sum F_{k} \sum_{k=1}^{n}\left[\left(Q^{e} / n\right){ }^{r} \mathrm{~F}^{k}\right]=\mathrm{Q}^{-} \sum_{k=1}^{n} F_{k}^{r} \text { and so } \sum_{k=1}^{n} F_{k}^{r}=\sum_{i=1}^{m} R_{i}
$$

The offer problem might be now expressed in terms of equivalent safety measure:

(equation 5)

$\operatorname{Max}^{\bar{p}}\left(\mathrm{~F}_{\mathrm{k}}-\mathrm{y}^{g}\right)+\mathrm{q}^{g} \mathrm{y}^{\frac{g}{k}}-\frac{a_{k}^{g}}{2} \operatorname{Var}\left(\mathrm{p}\left(\mathrm{F}_{\mathrm{k}}-\mathrm{y}^{\stackrel{g}{k}}\right)+\mathrm{q}^{g} \mathrm{y}^{\stackrel{g}{k}}\right)$

Where $\mathrm{a}^{g}$ - is the coefficient of risk refusal of the offer supplier.

The solution to the problem is:

$\mathrm{y}^{g}=\frac{q^{g}-\bar{p}}{a_{k}^{g} \sigma^{2}}+\mathrm{F}_{\mathrm{k}}=\left(\mathrm{F}_{\mathrm{k}^{-}} \frac{\bar{p}^{g}}{a_{k}^{g} \sigma^{2}}\right)+\frac{q^{g}}{a_{k}^{g} \sigma^{2}}=\mathrm{C}_{\mathrm{k}}+\mathrm{D}_{\mathrm{k}} \mathrm{q}^{g} \mathrm{ku}$

$\mathrm{C}_{\mathrm{k}}=\left(\mathrm{F}_{\mathrm{k}^{-}} \frac{\bar{p}^{\mathrm{g}}}{a_{k}^{g} \sigma^{2}}\right)$ dhe $\mathrm{D}_{\mathrm{k}}=\frac{1}{a_{k}^{g} \sigma^{2}}>0$

The trader owns the monopol in the contract market. He woutes a selling price for the consumer and a purchasing price for the offer supplier. He is neutral to the risk and so requires the maximum gain, that is achieved by the difference: selling price, purchasing price, multiplied by the sold amount. In this model all the trade is made among traders and so:

$Y=\sum_{i=1}^{m} Y_{i}^{s}=\sum_{k=1}^{n} Y_{k}^{g}$. So we have:

$A_{i}-B_{i} q_{c}=C_{k}+D_{k} q^{g}$ as consumption is always equal to selling or producing.

We rewrite as if we had one trader, one producer and one consumer, to put it simply and we observe that solving it for $\mathrm{q}^{\mathrm{c}}$ we have

$\mathrm{q}^{\mathrm{c}=} \frac{A-C}{B}-\frac{D}{B} q^{\mathrm{s}}$.

Now we consider the problem as the max problem, so

$\operatorname{Max}\left(q^{\mathrm{c}}-q^{\mathrm{g}}\right) \mathrm{y}$

Replacing, we have:

$\operatorname{Max}\left(\frac{A-C}{B}-\frac{D}{B} q^{g}-q^{g}\right)\left(\mathrm{C}+\mathrm{Dq} q^{\mathrm{g}}\right)=\frac{(A-C) C}{B}+\frac{(A-C) D q^{8}}{B}-\frac{D C q^{8}}{B}-\frac{D^{2}}{B}\left(q^{8}\right)^{2}-C q^{8}-D\left(q^{8}\right)^{2}$

Since $D>0$ and $B>0$ deriving in relation to $q^{9}$ we have

$\frac{(A-C) D}{B}-\frac{D C}{B}-\frac{2 D^{2}}{B} q^{8}-\mathrm{C}-2 \mathrm{Dq} \mathbf{q}^{\mathrm{g}}$

Knowing that the second derivate of the expression

$$
\frac{\Delta q^{g}}{q^{g}}=\frac{-2 D^{2} q^{g}}{B}-2 D q^{g}=\frac{-2 D^{2}}{B}-2 D<0
$$

Then the first condition is necessary for max so that

$$
\begin{aligned}
& \frac{(A-C) C}{B}+\frac{(A-C) D q^{g}}{B}-\frac{D C q^{g}}{B}-\frac{D^{2}}{B}\left(q^{g}\right)^{2}-C q^{g}-D\left(q^{g}\right)^{2}=0 \\
& \text { Or } \frac{2 D^{2} q^{g}}{B}+2 D q^{g}=\frac{A D-2 D C-B C}{B}
\end{aligned}
$$

Solving this equation in relation to $q^{9}$ we have

$$
\mathrm{q}^{\mathrm{g}}=\frac{A D-C(2 D+B)}{2 D(D+B)} .
$$

From this we take out q $\mathrm{q}^{\mathrm{C}}$

$q^{\mathrm{c}}=\frac{A-C}{B}-\frac{D}{B} q^{g}=\frac{A-C}{B}-\frac{D}{B}\left(\frac{A D-C(2 D+B)}{2 D(D+B)}\right)=\frac{A D+B(2 A-C)}{2 B(D+B)}$

So the condition is satisfying if

$\mathbf{q}^{\mathrm{C}}-\mathrm{q}^{\mathrm{g}}=\frac{A D+B(2 A-C)}{2 B(D+B)}-\frac{A D-C(2 D+B)}{2 D(D+B)}<0$

Until $B>0$ and $D>0$ then we have

$D(A D+B(2 A-C))<B(A D-C(2 D+B)$ 


\section{Or}

$A D^{2}+2 A B D-B C D<A B D-2 B C D-B^{2} C$

Or $A B D+A D^{2}+B C D+C B^{2}>0$

Simplifying suppositions even further, we admit that the offer suppliers have got the same risk acceptance coefficient. In the same way consumers have got the same risk coefficient.

So we have:

$\mathrm{a}^{g}=\mathrm{a}^{\mathrm{g}}$ and ${ }^{c}{ }^{c}=\mathrm{a}^{\mathrm{c}}$ so we have $\mathrm{A}=\mathrm{R}+\frac{m \bar{p}}{a^{c^{2}} \mathrm{~s}^{2}} ; \mathrm{B}=\frac{m}{a^{c} \mathrm{~s}^{2}} ; \mathrm{C}=\mathrm{F}-\frac{n \bar{p}}{a^{g} s^{2}} ; \mathrm{D}=\frac{n}{a^{g} s^{2}}$ for $\mathrm{k}=1 \ldots \mathrm{n}$ and $\mathrm{i}=1 \ldots . \mathrm{m}$ and $\mathrm{so}$ $\mathrm{ABD}+\mathrm{AD} \mathrm{D}^{2}+\mathrm{BCD}+\mathrm{CB}^{2}=$

$\left(\mathrm{R}+\frac{m \bar{p}}{a^{c} s^{2}}\right) \frac{m}{a^{c} s^{2}} \frac{n}{a^{g} s^{2}}+\left(\mathrm{R}+\frac{m \bar{p}}{a^{c} s^{2}}\right)\left(\frac{n}{a^{g} s^{2}}\right)^{2}+\frac{m}{a^{c} s^{2}} \times\left(\mathrm{F}-\frac{n \bar{p}}{a^{g} s^{2}}\right) \frac{n}{a^{g} s^{2}}+\left(\mathrm{F}-\frac{n \bar{p}}{a^{g} s^{2}}\right) \mathrm{X}$

$\mathrm{X}\left(\frac{m}{a^{c} s^{2}}\right)^{2}$

Making the accpmpanying calculations, the above expression is transformes in the below form:

$=(\mathrm{R}+\mathrm{F})\left(\frac{m}{a^{c} s^{2}}\right)\left(\frac{n}{a^{g} s^{2}}\right)+\mathrm{R} \frac{n}{a^{g} s^{2}}+\mathrm{F} \frac{m}{a^{c} s^{2}}>0$

This proves the limitations that satisfy the optimum.

Let us go back to the offer equation once again, so in q $^{9}$

$\mathrm{q}^{\mathrm{g}}=\frac{A D-C(2 D+B)}{2 D(D+B)}=\frac{\frac{\left(R+\frac{m \bar{p}}{a^{c} s^{2}}\right)\left(\frac{n}{a^{g} s^{2}}\right)-\left(F-\frac{n \bar{p}}{a^{g} s^{2}}\right)\left(2 \frac{n}{a^{g} s^{2}}+\frac{m}{a^{c} s^{2}}\right)}{2 \frac{n}{a^{g} s^{2}}\left(\frac{n}{a^{g} s^{2}}+\frac{m}{a^{c} s^{2}}\right)}}{a^{2}}$

Transforming it we have

$\mathbf{q}^{g}=\bar{p}+\frac{R-F}{2\left(\frac{n}{a^{g} s^{2}}+\frac{m}{a^{c} s^{2}}\right)}-F \frac{a^{g} s^{2}}{2 n}$

Knowing that $\mathrm{R}=\mathrm{F}$ then the expression $\mathrm{q}^{\mathrm{g}}={ }^{\bar{p}-F} \frac{a^{g} s^{2}}{2 n}$

Identically we deal with the request equation and we have:

$\mathrm{q}^{\mathrm{c}=} \frac{A D+B(2 A-C)}{2 B(D+B)}=\frac{\left(R+\frac{m \bar{p}}{a^{c} s^{2}}\right)\left(\frac{n}{a^{g} s^{2}}\right)+\frac{m}{a^{c} s^{2}}\left[2\left(R+\frac{m \bar{p}}{a^{c} s}\right)-\left(F-\frac{n \bar{p}}{a^{g} s^{2}}\right)\right]}{2 \frac{m}{a^{c} s^{2}}\left(\frac{n}{a^{g} s^{2}}+\frac{m}{a^{c} s^{2}}\right)}=$

$=\quad \bar{p}+R \frac{a^{c} s^{2}}{2 m}+\frac{R-F}{2 \frac{n}{a^{g} s^{2}}+\frac{m}{a^{c} s^{2}}}$

Knowing that $\mathrm{R}=\mathrm{F}$ then $\mathrm{q}^{\mathrm{c}}=\bar{p}+R \frac{a^{c} s^{2}}{2 m}$

From this equation w might also find $\mathrm{y}_{\mathrm{i}}$ starting from equation 3 and we have

$\mathrm{y}^{i}=\mathrm{Ri}+\frac{\bar{p}}{a^{c} \sigma^{2}}-\frac{q^{c}}{a^{c} \sigma^{2}}$ since $=\sigma$ we write

$\mathrm{y}^{i}=\mathrm{R}_{\mathrm{i}+} \frac{\bar{p}}{a^{c} s^{2}}-\frac{1}{a^{c} s^{2}}\left(\bar{p}+R \frac{a^{c} s^{2}}{2 m}\right)=\mathrm{Ri}_{\mathrm{i}}-\frac{R}{2 m}$

In the same way for the offer

$y_{k}^{g}=\left(\mathrm{F}_{\mathrm{k}^{-}} \frac{q^{g}}{a_{k}^{g} \sigma^{2}}\right)+\frac{q^{g}}{a_{k}^{g} \sigma^{2}}=\mathrm{F}_{\mathrm{k}^{-}} \frac{\bar{p}}{a^{g} s^{2}}+\frac{1}{a^{g} s^{2}}\left(\bar{p}-F \frac{a^{g} s^{2}}{2 n}\right)=\mathrm{F}_{\mathrm{k}^{-}}-\frac{F}{2 n}$

Lastly we calculate the price difference selling vs purchasing

$\mathrm{d}=\mathrm{q}^{\mathrm{c}}-\mathrm{q}^{\mathrm{g}}=\bar{p}+R \frac{a^{c} s^{2}}{2 m}-\left(\bar{p}-F \frac{a^{g} s^{2}}{2 n}\right)=R \frac{a^{c} s^{2}}{2 m}+F \frac{a^{g} s^{2}}{2 n}=\frac{s^{2}}{2}\left(R \frac{a^{c}}{m}+F \frac{a^{g}}{n}\right)$

Equaling $\mathrm{R}=\mathrm{F}$ we have

$\mathrm{d}=\mathrm{F}^{\frac{s^{2}}{2}}\left(\frac{a^{c}}{m}+\frac{a^{g}}{n}\right)$

So, just as it is showed the forward price of fuel sold (by the offer supplier) is lower than the predicted spot, while the price purchased by the consumer is higher than the expected spot price. In accordance to this offer suppliers sell less 
production than their capacities, while consumers purchase less through contracts than their fuel consumption. The non accepting risk agents wish to be protected from risk. In our model they achieve that through the contract market and for each factor that increases risk (the exposure to risk) or makes these agents fight risk more in increasing their request for protection affecting contract prices. What is more, these results are not a surprise:

1. The contract price paid from (to) a consumer (offer supplier) is higher (lower) depending on how much he accepts risk. This makes sense because a non accepting risk agent signs for more money in order to be less exposed to the market spot prices.

2. The forward price paid from (to) a consumer (offer supplier) is higher (lower), depending on how wide the variance of spot prices is, as it implies more risk.

3. The contracted price paid from (to) a consumer (offer supplier) is higher (lower) depending on the total of consumption (production) for a given number of consumers (offer suppliers). When average consumption (production) is higher, each consumer (offer supplier) should individually trade more fuel in the market and this increases his exposure risk.

An interesting result might be achieved leaving hte number of consumers "m“, while the increase of the total demand for fuel does not change. This gives an answer to the case when some safe consumers leave a regular, set market for a market of cheap contracts. Since $n$ does not change, then even by definition $F=R$, then the price of fuel sold forward does not change, even when leaving becomes a fact.

On the other hand, bringing the price of purchased fuel in the forward way depends on what happens to the value $\mathrm{R} / \mathrm{m}$. If it does grow after the leaving, then $\mathrm{q}^{\mathrm{c}}$ grows. If it decreases $\mathrm{q}^{\mathrm{c}}$ decreases too. Lastly it would be a surprise result, if the trader has got a monopolistic power in the contract market. The explanation is that since average consume goes down, the average consume is less exposed to the risk of spot price. As a result, the elasticity of demand for contracts increases, but risk sharing becomes less important to the average consumer.

Let us go back to the trader. First, it is noticed that distribution $d$ is strictly positive and as expected it grows further with the risk non acceptance ratio from the offer suppliers, that of sonsumers and the variance of spot price. What is more, since half of fuel amounts has been traded in the contract market, the gain of the trader is equal to

$$
\mathrm{p}_{\mathrm{d}}=\mathrm{dy}=\frac{s^{2}}{2}\left(R \frac{a^{c}}{m}+R \frac{a^{g}}{n}\right)\left(\frac{R^{*}}{2}\right)=\mathrm{R}^{2} \frac{s^{2}}{4}\left(\frac{a^{c}}{m}+\frac{a^{g}}{n}\right)
$$

It is noticed that $\mathrm{y}=\sum_{k=1}^{m} y_{1}^{c}=\sum_{k=1}^{m}\left(R_{i}-\frac{R}{2 m}\right)=R-\frac{R}{2}=\frac{R}{2}$

So, when there are leaves in the free market, what happens to the gain, depends on the behaviour of average consumption.

Contract market with more than one trader

The monopole trader gains a strictly positive margin and as a result, positive gain through operating in the forward market. This will appeal to other companies entering the market as traders.

So, $T$ identical traders now, play a Cournot game. The gain function of trader $t$ is $p_{h}=\left(q^{c}-q^{g}\right) y^{m}$ where $y_{t}^{m}$ is the quantinty of traded fuel from the $t$ trader.

Trader $\mathrm{t}$ should solve the problem below where $\mathrm{y}=\sum_{t=1}^{n} y_{t}^{m}$

$\operatorname{Max}\left(\left(q^{c}-q^{g}\right) y^{m}\right)$

In conditions when $\mathrm{y}=\mathrm{A}-\mathrm{Bq}{ }^{\mathrm{C}}=\mathrm{C}+\mathrm{Dq} q^{9} \quad 2-1$

The problem is equivalent to

$\left.\operatorname{Max}\left(\frac{A-y}{B}-\frac{y-C}{D}\right) y_{t}^{m}\right) \quad 2-2$

Where limitations have now been set in the objective function.

We finish this proposal. Balance quantities and prices in a forward market where

a- Offer supplier are price accepting

b- There are many traders playing the Cournot game

c- All offer suppliers have og the same risk acceptance coefficient

Then, we might rewrite the problem:

$\operatorname{Maxy}^{m}\left(\frac{A D+B C-(D+B) y}{B D}\right) y_{t}^{m}$

The other first condition to this problem is

$-\frac{(D+B)}{B D} y_{t}^{m}-\frac{A D+B C-(D+B) y}{B D}=0$ 
We might rewrite this expression:

$-(\mathrm{D}+\mathrm{B}) \mathrm{y}^{t}+\mathrm{AD}+\mathrm{BC}-(\mathrm{D}+\mathrm{B}) \mathrm{y}^{t}-(\mathrm{D}+\mathrm{B}) \sum_{j=1}^{\sum_{j=1}^{m} y_{j}^{m}}$

So, has been set apart this expression $(\mathrm{D}+\mathrm{B}) \mathrm{y}=(\mathrm{D}+\mathrm{B}) \mathrm{y}^{\frac{m}{t}}-(\mathrm{D}+\mathrm{B}) \sum_{j=1}^{m-1} y_{j}^{m}$

From it we have:

$-2 \mathrm{y}^{m}(\mathrm{D}+\mathrm{B})+\mathrm{AD}+\mathrm{BC}-(\mathrm{D}+\mathrm{B}) \sum_{j=1}^{m-1} y_{j}^{m}=0$

Or

$\mathrm{y}^{m}=\frac{A D+B C}{2(D+B)}-\frac{\sum_{j=1}^{m-1} y_{j}^{m}}{2}$

Since we have agreed that traders are symmetrical, then $\mathrm{y}^{t}=\frac{y}{m}$ dhe $\sum_{j=1}^{m-1} y_{j}^{m}=\frac{(T-1)}{T} y$

So, we can rewrite:

$\mathrm{y}^{t}=\frac{A D+B C}{2(D+B)}-\frac{(T-1) y}{2 T}$

or

$\mathrm{y}=\frac{T(A D+B C)}{2(D+B)}-\frac{T(T-1) y}{2 T}$ from where

$\mathrm{y}+\frac{(T-1) y}{2}=\frac{T(A D+B C)}{2(D+B)}$ doing the calculations we have:

$\mathrm{y}+\frac{(T-1) y}{2}=\frac{T(A D+B C)}{2(D+B)}=\frac{(T+1) y}{2}=\frac{T(A D+B C)}{2(D+B)}$

$\mathrm{y}=\frac{T(A D+B C)}{2(D+B)} x \frac{2}{T+1}=\frac{T(A D+B C)}{(T+1)(D+B)}$

Or $\mathrm{y}^{m}=\frac{y}{T}=\frac{A D+B C}{(T+1)(D+B)}$

Now we replace A, B, C, D in the above formula and we get:

$\mathrm{y}_{i}^{m}=\frac{\left(R+\frac{m \bar{p}}{a^{c} s^{2}}\right)\left(\frac{n}{a^{g} s^{2}}\right)+\left(\frac{m}{a^{c} s^{2}}\right)\left(F-\frac{n \bar{p}}{a^{g} s^{2}}\right)}{(T+1)\left(\frac{n}{a^{g} s^{2}}+\frac{m}{a^{c} s^{2}}\right)}=\frac{\left(R \frac{n}{a^{g} s}+\frac{n m \bar{p}}{a^{g} a^{c}\left(s^{2}\right)^{2}}\right)+\left(\frac{F m}{a^{c} s^{2}}-\frac{m n \bar{p}}{a^{c} a^{g}\left(s^{2}\right)^{2}}\right)}{(T+1)\left(\frac{n}{a^{g} s^{2}}+\frac{m}{a^{c} s^{2}}\right)}=\frac{F\left(\frac{n}{a^{g} s}+\frac{m}{a^{c} s^{2}}\right)}{=}={ }^{(T+1)\left(\frac{n}{a^{g} s^{2}}+\frac{m}{a^{c} s^{2}}\right)}=\frac{F}{(T+1)}$

So $\mathrm{y}^{t}=\frac{F}{(T+1)}$ while $\mathrm{y}=\mathrm{T} \mathrm{y}^{t}=\frac{T F}{(T+1)}$

The next step is calculating prices:

$$
\begin{aligned}
& \mathrm{q}^{\mathrm{c}}=\frac{A-y}{B}=\frac{R+\frac{m \bar{p}}{a^{c} s^{2}}-\frac{T F}{(T+1)}}{\frac{m}{a^{c} s^{2}}}=\bar{p}+\frac{R a^{c} s^{2}}{m}-\frac{T F a^{c} s^{2}}{m(T+1)}=\bar{p}+R \frac{a^{c} s^{2}}{m}\left(\frac{1}{(T+1)}\right) \\
& =\frac{\frac{T F}{T+1}-\left(F-\frac{n \bar{p}}{a^{g} s}\right.}{\frac{n}{a^{g} s^{2}}}=\bar{p}_{-}^{\frac{F\left(\frac{T}{T+1}-1\right)}{\frac{n}{a^{g} s^{2}}}=\bar{p}-F^{-} \frac{a^{g} s^{2}}{n(T+1)}}
\end{aligned}
$$

The margin might be easily be measured.

$\mathrm{D}=\mathrm{q}^{\mathrm{C}}-\mathrm{q} \mathrm{g}={ }^{\bar{p}+R \frac{a^{c} s^{2}}{m}\left(\frac{1}{(T+1)}\right)}-\bar{p}_{-}-\frac{a^{g} s^{2}}{n(T+1)}=\mathrm{F} \frac{s}{T+1}\left(\frac{a^{c}}{m}+\frac{a^{g}}{n}\right)$

The amount contracted by offer suppliers and consumers is now calculated:

$y_{k}^{g}=F_{k}-\frac{\bar{p}}{a^{g} s^{2}}+\frac{1}{a^{g} s^{2}}\left(p-F \frac{a^{g} s^{2}}{n(T+1)}\right)=F_{k}-\frac{F}{n(T+1)}$

And

$y_{k}^{c}=R_{i}+\frac{\bar{p}}{a^{c} s^{2}}-\frac{1}{a^{c} s^{2}}\left(\bar{p}+R \frac{a^{c} s^{2}}{m}\left(\frac{1}{(T+1)}\right)=R_{i}-\frac{R}{m(T+1)}\right.$

Lastly we can calculate:

That $\sum_{k=1}^{n} y_{k}^{g}=\sum_{k=1}^{n} F_{k}-\frac{F}{n(T+1)}=F-\frac{F}{T+1}=F \frac{T}{T+1}$

And 


$$
\begin{aligned}
& \sum_{k=1}^{n} y_{i}^{c}=\sum_{k=1}^{n} R_{i}-\frac{R}{m(T+1)}=R-\frac{R}{T+1}=R \frac{T}{T+1} \\
& \text { And } \\
& \sum_{k=1}^{n} y_{t}^{m}=\sum_{t=1}^{T} \frac{F}{T+1}=F \frac{T}{T+1}
\end{aligned}
$$

As about the fact how much they depend on the scale of risk acceptance and the variance they have to deal with, amounts and prices bought and sold forward have got the same specifics to those in which was caracterized the monopoly market case. This result of the second proposal is the same when $T=1$. The total amount of traded fuel trough forward contracts is again less than the available quantity for sale, not more than exactly half of it.

We aim at the effects of a wide number of traders in the balance values. Easily understandable, the price of bought fuel decreases with the number of traders. This is exactly what the cournot model produces. The more traders there are, the stronger the competition among them and this decreases the price they offer to the consumers. At the limit they might spent not more than the expected spot price.

In analogy to this, the fuel price with forward contracts, increases with the number of traders, again as a result of the increased competition among traders. At the limit it is not surprising that the margin spent from traders goes toward zero when the number of traders increases infinitely.

Inspecting the formulae for $y_{i}^{c}$ and of $y_{k}^{g}$, we immedieately notice that as soon as the number of traders increases, the fuel sold forward from an offer supplier achieves its net production, while fuel ought forward from one consumer reaches its actual consumption. This is not an important effect starting from the fact that since the price paid by the consumer goes down while the price paid by the offer supplier goes up with the increased numer of traders, offer suppliers face strong incentives to protect teir positions in the contract market.

As soon as the number of traders goes up, portofolios kept fromindividual traders decrease in measures and the total of the sold fuel in the contract market goes towards the real needs of the market. This is expected, since both parties, either consumers and offer suppliers face trade with all the energy they need or respectively have. This shows that the role played by the spot market has got the tendency to decrease because of the growth of competition among traders.

\subsection{The Albanian case}

The Albanian case has got the form of oligopol. The fact that fuel prices have had an increasing tendency with $15 \%$ for each year during 1998-2014, which shows that the situation in this market shows that the most part of relatioships among producers, traders and small amount sellers reflect the fact that the contract market is very little developed which tends to orient more towards the spot prices making contracts much wanted. At the moment when these contracts will increase, it will be noticed that their margins with decrease. Which brings the necessity of legal amendaments.

See how the price has changed from 1998 to 2012

\begin{tabular}{|c|c|c|c|c|c|c|c|c|c|}
\hline Year & $\mathbf{1 9 9 8}$ & $\mathbf{2 0 0 0}$ & $\mathbf{2 0 0 2}$ & $\mathbf{2 0 0 4}$ & $\mathbf{2 0 0 6}$ & $\mathbf{2 0 0 8}$ & $\mathbf{2 0 1 0}$ & $\mathbf{2 0 1 2}$ & Average annual growth \\
\hline Albania & 0.86 & 0.57 & 0.8 & 1.23 & 1.44 & 1.36 & 1.46 & 1.81 & $15 \%$ \\
\hline
\end{tabular}

Open data Source

If we compare them to the consume, it is decreasing as a result of the pressure that the increased price has an effect on the demanded quantity. (This includes over 95\% of the country's needs) The country produce has known the biggest decrease after the year 2008, which does not ruin our conclusions.

\begin{tabular}{|c|c|c|c|c|c|c|}
\hline Year & 2008 & 2009 & 2010 & 2011 & 2012 & 8 -months 2013 \\
\hline Imported Quantity & 436971.00 & 432132.00 & 484392.00 & 457250.00 & 431858.00 & 358821.00 \\
\hline
\end{tabular}

\section{Conclusions}

First of all we reached the results, that are standards in literature. Paid prices paid be the consumer are increasing in their scale of risk refusal and of variance of the spot price, while prices of offer suppliers sell forward fuel with a decrease for the same indicators. We also presented the case of a monopolist trader who will be able to decrease price producing a positive margin and this increases to the risk refusal of furnishers an consumers and as well with the variance of the spot price. 
A main contribution comes from analysing what happens when the number of consumers in contracts increases, which in our model correspond to a scenario where sure consumers migrate from a settled market to a contract market and there are no changes in the total demand for fuel.

One of the consequences is that the fuel price sold through contracts decreases, which in other unchanged conditions hurts the offer supplier. As about the effects on the price of fuel bought with contract, it depends on the behaviour of the average consume. If average consume is higher after the migration, then the price that the consumer pays increases. If average consume is lower then it decreases. The second case is not a standard result when the trader has got monopolistic power in the contract market. To understand it, it is noticed that when the average consume decreases, then the average consume is less exposed to the risk of the spot price. This means that sharing the risk becomes less important to it and in this way traders face increasing competition from the spot market, which weakens their market power.

An important contribution is the presentation that the total quantity of traded energy in the contract market treats the necessary fuel as an increasing number of traders. This means that spot markets might become less important, when there is an increased competition among traders in the contract market and there is something to be fixed.

Lastly it was presented that the price of purchased fuel through contracts decreases with the number of traders. The more traders there are, the stronger the competitions among them and so, they will decrease prices for the consumers. At the limit they might decrease prices not more than the expected spot price. In analogy, the price of forward sold fuel increases with the number of traders and equals the spot pride as a limit.

There can be found many ways to improve this model. We took a look on the opportunity of investigated issues such as strategical interaction between markets of settled and free contract markets, the price competitions among traders and others.

\section{References}

Fondamentals of corporate Finance. Autor Stephen Ross, Randolph Weterfield, Bradford Jordan. Trading Forward in the Brazilian Electricity Market. Autor; Paulo Coutinho, Andre Rossi de Oliveira Microekonomia 1- Alqi Naqellari

What Next for the Oil and Gas Industry? Autor;John Mitchell with Valérie Marcel and Beth Mitchell BP Statistical Review of World Energy June 2013

Risk Management with Futures Contracts. David Dubofsky and Thomas W. Miller, Jr Fundamentals of Trading Energy Futures \& Options, 2nd Edition Steven Errera and Stewart Brown Creating Competitive Power Markets: The PJM Model Jeremiah D. Lambert Intermediate mikroekonomic analysis . teory and applications Evans Dougllas. Oil and gas law and taxation Anderson, Dzienkovski,lowe,Peroni, Pierce,Smithe International Energy Markets: Understanding Pricing, Policies, and Profits Carol Dahl The upward trend in the price of gasoline versus oil in Albania and in the world 1998-2012 (Open Data) Konsumi i energjisë së hidrokarbureve në Shqipëri dhe në Botë në vitet 1971-2010. (Open data) 